\title{
Economic Development and Social Media: A Strategic Approach for Success
}

\author{
Sara Chamberlain, Ec.D.
}

The use of social media for personal, professional and business purposes is rising quickly, as are the number of tools available. Economic development agencies have an excellent opportunity to use social media to effectively deliver their programs and services. Social media tools provide timely, engaging, interactive, targeted and low-cost ways to market a community, gain intelligence, and communicate and build relationships with stakeholders. To make effective use of social media, economic developers must understand the underlying purpose of social media and develop strategies to implement it effectively. Using research and recommendations from social media experts in a variety of disciplines, this paper examines how social media has changed marketing and communications, the purpose of social media, possible applications of social media in economic development, and how to develop an effective social media strategy. By taking a strategic approach to social media, economic developers can use it to achieve their goals.

Keywords: social media, economic development, social media strategy, tools and techniques, investment attraction marketing

\section{Introduction}

In just a decade, social media has grown from its status as a collection of trendy, technologydriven online tools used by early adopters, to a mainstream form of communication used in everyday life, across Canada and the United States.

As citizens have migrated to the Internet to take advantage of the immediacy and interactivity of social media to stay connected, so too have marketers, communicators, businesses and other professionals. Today, social media is not just a tool to have personal conversations and share photos between family and friends; it is also a resource to gain information, insights, and advice for personal and professional decision-making. It is also a way to make and build connections with people around the world for both personal and professional gain.

Social media offers economic developers the opportunity to start conversations and make connections that can ultimately help their agency or community achieve its goals. If understood effectively and used strategically, social media can be a powerful tool for economic developers.

\section{What is Social Media?}

Social media encompasses a variety of Internet-based technologies such as social networking sites, blogs and microblogs, content communities, collaborative projects and even virtual game 
worlds (Kaplan and Haenlein, 2010). There are many different forms including podcasts, wikis, magazines, and social networks, to name just a few. There are hundreds of social networking services, or sites, that house this technology including these popular platforms: Facebook, Twitter, LinkedIn, YouTube, Pinterest and Instagram ("Social Networking Service," 2014).

The term "social media" was first used in 2004. It's defined, according to Merriam Webster (2014), as

forms of electronic communication (as Web sites for social networking and microblogging) through which users create online communities to share information, ideas, personal messages, and other content (as videos).

This is a very clinical definition of social media. Put another way, "social media is digital content and interaction that is created by and between people" (Cohen, 2011).

\section{Use of social media}

Seventy-three percent of online adults in the United States use a social networking site of some kind, according to research published in January 2014 (Duggan \& Smith). Canadian statistics are similar. In Canada, $69 \%$ of the country's population visited at least one social networking site in 2013, up three percent from the year before (Canadian Internet Registration Authority, 2014).

Reports such as these show substantial increases in social media, and general Internet, use yearover-year, both in time spent using social media and the number of tools employed. In the United States, $42 \%$ of online adults use two or more social media networks (Figure 1), and the majority access them daily. In Canada (Figure 2), social media is the number one or two ranked activity performed on a variety of electronic devices (CIRA 2014).

\section{Figure 1: Number of social media sites used by online adults in the United States} (\% of Internet users)

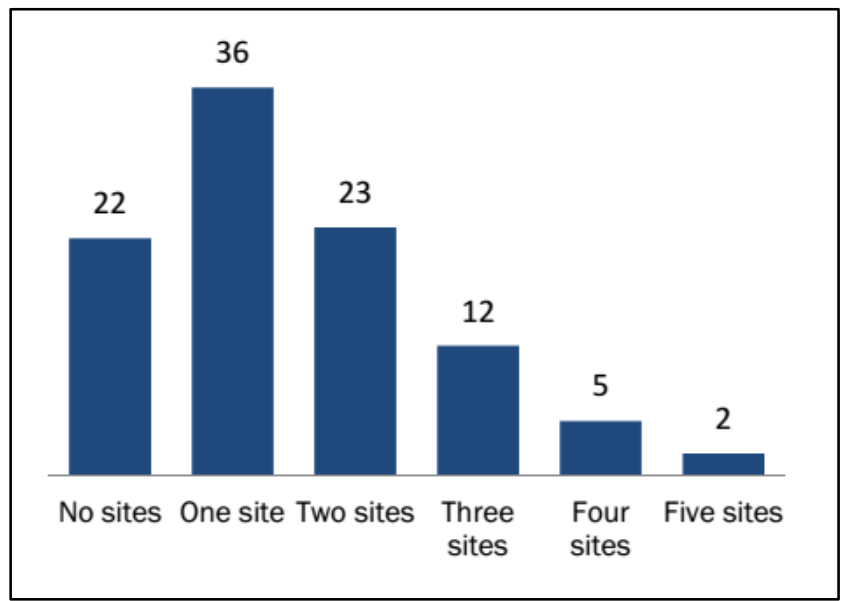

Source: Pew Research Center, Social Media Update 2013 
Figure 2: What Canadians are doing online by device, 2013

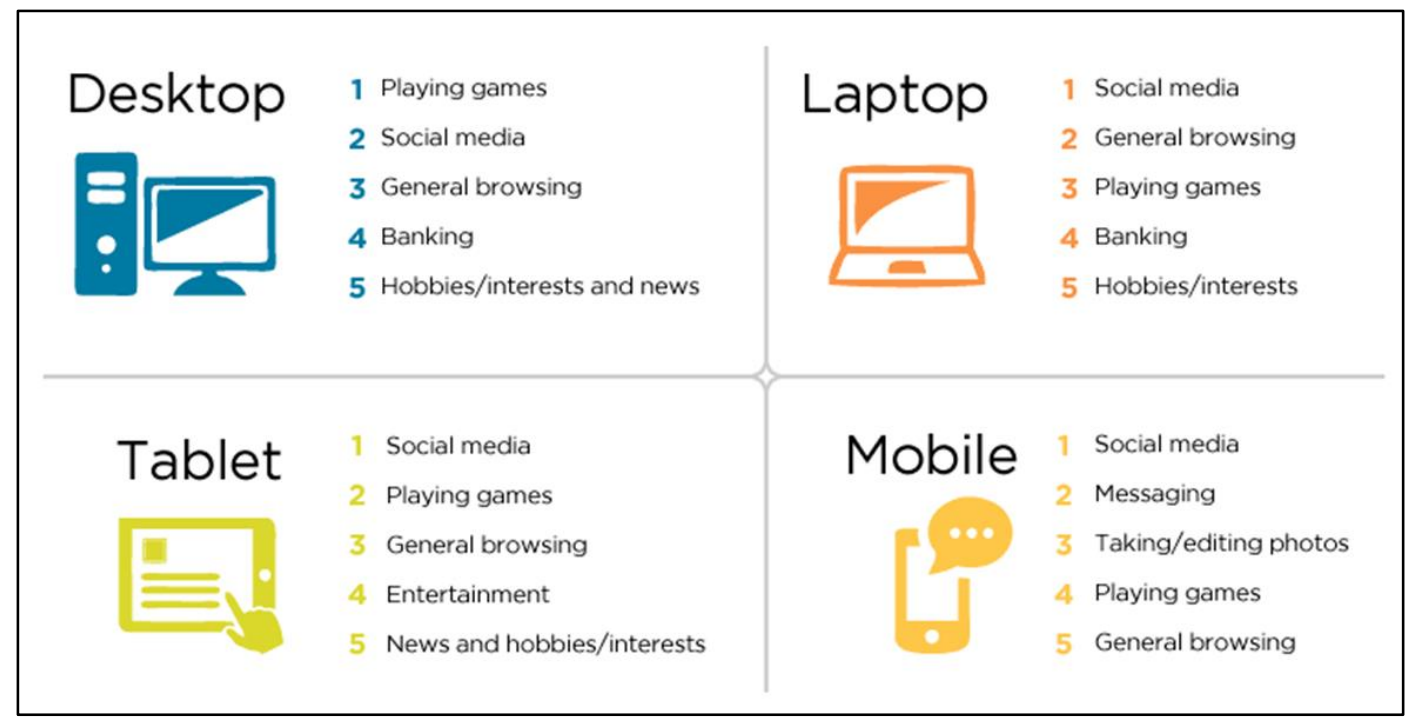

Source: CIRA, 2014

Individuals aren't the only users. Business use is also growing quickly. Statistics Canada (2014) reports that $38 \%$ of enterprises with a website (91\% of Canadian businesses have a website) had social media integration, an increase of five percent from 2012. This includes businesses of all sizes. In Alberta, for example, $35 \%$ of small and medium-size enterprises report that they currently use social media for business purposes. That's up from just eight percent three years ago. Thirty-one percent of businesses expect they will use social media more in the next year (ATB Financial, 2014).

\section{Social Media Has Changed Business, Marketing and Communications}

Without question, social media has changed the face of business, marketing and communications. Dave Evans (2010), author of Social Media Marketing: The Next Generation of Business Engagement, calls the advent of social media a "game changer."

The well-established norms of business marketing have undergone a forced change. No longer satisfied with advertising and promotional information as a sole source for learning about new products and services, consumers have taken to the Social Web in an effort to share among themselves their own direct experiences with brand, products, and services to provide a more "real" view of their research experience. (Evans, p. 4)

Evans illustrates his point using the "Social Feedback Cycle" (Figure 3). He connects the classic "purchase funnel" that is awareness, followed by consideration and then purchase with the social media feedback loop, which relies heavily on sharing opinions, conversation and information exchange. 
This cycle, Evans purports, is the basis of what he calls "social business."

Social media marketing - properly practiced - seeks to engage customers in the online social locations where they naturally spend time. By comparison, social business picks up on what they are talking about and what they are interested in and connects this back into the business where it can be processed and used to create the next round of customer experiences and hence the next round of conversations. (Evans, p. 6)

Figure 3: The Social Feedback Cycle

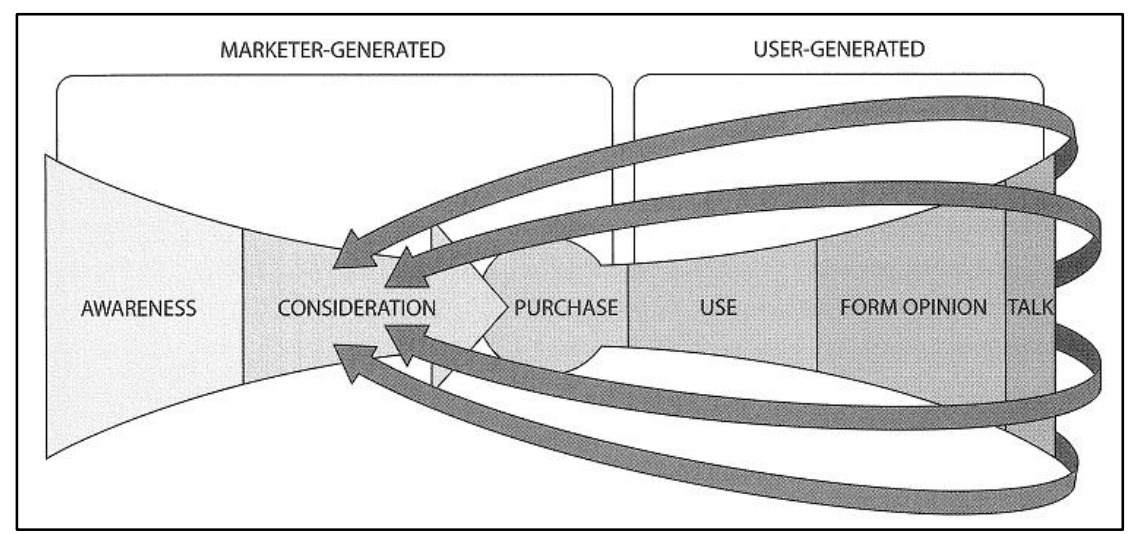

Source: Social Media Marketing, 2010

\section{Professionals' use of social media}

Marketers have been quick to use, and attempt to leverage, social media. The 2014 Social Media Marketing Industry Report (Stelzner, 2014) showed 97\% of marketing professionals use social media for their business. More importantly, perhaps, is that $92 \%$ say social media is important to their business, an increase from $86 \%$ in 2013.

The amount of time marketers spend using social media is also rising. The majority, 64\%, use it for six hours a week, up from $62 \%$ the previous year. It should be noted that $19 \%$ of marketers spend more than 20 hours a week on social media (Stelzner, 2014).

Marketers are not alone. Communications professionals have also seen the opportunity that lies with social media. Social media allows companies and organizations "to communicate directly and instantly with their stakeholders, marking a shift from the traditional one-way output of corporate communications, to an expanded dialogue between company and consumer" (Matthews, 2010, p. 10).

\section{Social media is about relationships}

Numerous social media platforms are in existence. From the mainstays of Facebook, LinkedIn, Twitter and YouTube to fast-rising applications such as Medium, Tinder and Vine (Singh, 2014), the social media landscape is full of new options and new technology. 
However, experts agree social media is not about technology, it's about relationships. Evans says the central aspect to social business is the development of connections between people.

Connections, he continues, lead to engagement online. He defines engagement in social business as "your customers are willing to take their time and energy and talk to you-as well as about you - in conversation and through processes that impact your business. They are willing to participate, and it is this participation that defines engagement in the context of the social web" (Evans, p. 11).

\section{Economic Development Use of Social Media}

Economic development organizations and economic development professionals across Canada and the United States play a variety of roles in their communities and regions. The duties of an economic developer range widely from strategic planning to business counseling to investment attraction marketing. As with marketers and corporate communications professionals, social media has become an important instrument in the economic developer's toolbox.

\section{Economic developers are using social media}

Like other professionals, economic developers are adopting social media. Information from the Economic Developers Association of Canada (EDAC, 2014) shows its members are using social media for both gathering information relevant to their work and promoting their communities or organizations (Figure 4).

\section{Figure 4: Social media platforms EDAC members are using (\% of respondents)}

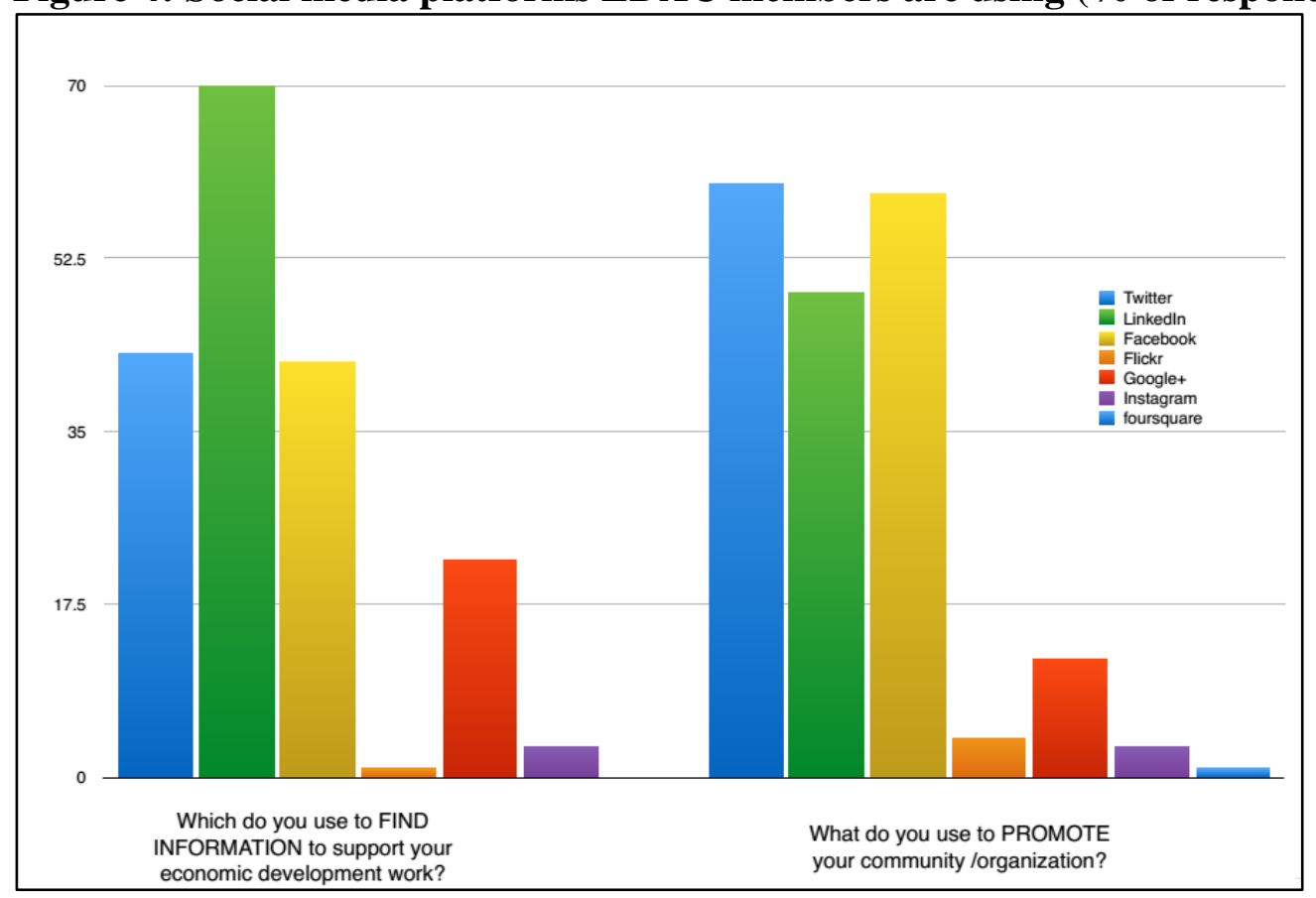

Source: Economic Developers Association of Canada, 2014 


\section{Creating conversations}

In High Performance Economic Development: How Technology and Outcome-Based Metrics Will Save Economic Development Investment and Promotion as We Know It (Wright, 2012), the case is made for the importance of using social media to ultimately generate jobs and investment in a community or region.

Wright, who collected and analyzed data from over 100 communities in the United States and Europe, developed a framework for high performing economic development organizations. The model suggests that the one single metric that drives economic development results more than any other is having a meaningful conversation (2012, p. 17).

\section{Figure 5: High Performance Economic Development Framework}

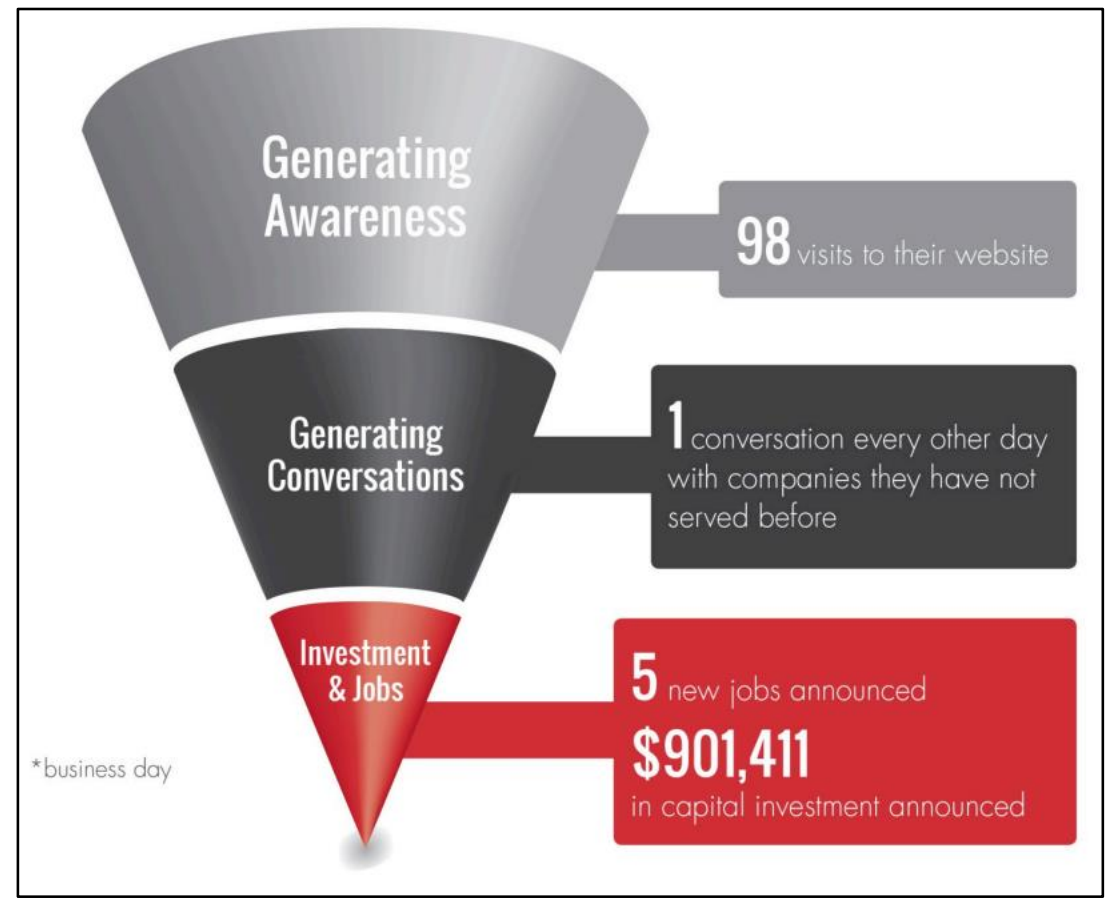

Source: Wright, 2013

Wright used four metrics to create this framework: 1) unique website visits, 2) conversations (defined as discussions with prospective, existing or entrepreneurial companies who are expanding or relocating), 3) jobs, and 4) capital investment announced in a community. His theory suggests that economic developers get the most bang for their buck through the relationships they build. "If we are not having conversations, we are not making a difference," says Wright (2013). "The ways we start having conversations has changed forever."

As with Evans' Social Feedback Cycle, Wright points to social media as catalyst for creating conversations. 


\section{Applications of social media in economic development}

Just as the mandates and goals of economic development agencies vary widely, so do the social media applications that are available to economic developers. Economic developers can, and do, use social media for a variety of purposes.

\section{Reputation management}

Managing an organization's reputation is an important part of operating an economic development agency. Social media offers opportunities to find out what are people are saying, and to respond if necessary.

Social media monitoring tools can be a defensive mechanism as well as a signpost for progress. They can alert EDOs to sudden changes in volume and tone of conversations using real-time measurements. If you're not monitoring what is being said about you, how will you be able to respond if trouble erupts from some unexpected source? (Seed, 2013)

Further, social media monitoring tools make keeping tabs on one's reputation easier and quicker than traditional methods. Economic developers using automated tools are able to monitor social media channels by location, date or even time, and can analyze the content and tone of what's being said. Many tools allow users to aggregate results and store them for long-term analysis of trends (Seed, 2013).

\section{Media monitoring and news dissemination}

Like reputation management, social media takes media monitoring to a new level in terms of timeliness, amount, and type of information collected. What once could have taken an economic developer one full day to scan local news sources for information about prospective investors or local businesses can now be automated and found in mere seconds using online tools.

Social media provides fast and targeted channels for dissemination of news, both to traditional and new media sources. Over the past decade, the size of newsrooms has shrunk $30 \%$ (Holtz, 2012), resulting in fewer reporters to cover an economic development agency's news. Social media aids tremendously in delivering news, and it allows economic developers to be more targeted. While traditional news media continue to report a few types of news (i.e. business, sports, lifestyle), the Internet now houses a plethora of niche topics (i.e. religion, politics, industries). This gives economic developers the opportunity to easily circulate news stories to niche groups and to mine information on specific target industries or individuals.

\section{Market intelligence to develop relationships}

Building on news and media monitoring, social media provides a fantastic opportunity for economic developers to gather market intelligence. Not only do social sites allow economic 
developers to learn basic information (i.e. expansion plans, new products, awards and milestones) about businesses in their community or ones they are targeting for investment, they are critical to helping economic developers understand their clients on a more personal level and build relationships with them.

Your clients use social media via numerous platforms multiple times a day. They are having intelligent discussions on LinkedIn, joining causes on Facebook, and sharing their thoughts to the world through Twitter. It is possible to connect with top executives in meaningful discussions and transition that interest to a webinar that allows you to discuss your region. When it is time to meet in person you're not starting from scratch but rather building capacity. In short, you are much farther down the sales cycle and can determine when and where to spend your money on face to face meetings. (Hart, 2012)

\section{Workforce attraction}

Also referred to as talent, labour, or creative class attraction, many economic developers are tasked with attracting the right people to their community, and retaining them. It is believed that creative class individuals use social media more than average (Seed, 2012a). This presents the opportunity for economic developers to identify and reach prospective residents online and direct them to tools such as job postings and educational and networking events (Seed, 2012b). Social media is also a very powerful tool to showcase a community's quality of life through video, discussions, testimonials, ratings, and conversation.

\section{Public engagement}

Economic developers are often responsible for organizing or contributing to public engagement or consultation processes. Whether it's the creation of an economic development strategy or a land use rezoning application, public input is critical to economic development. Chief strategist for San Jose, California, Kim Walesh, describes the benefits of social media in public consultation:

The whole underlying philosophy of social media is that there is intelligence in the crowd; and there is creativity in the crowd.... There is power in inputting an idea out there and having others work the idea and improve on it. Good ideas can come from anywhere in the community. (Kingsley, 2009, p. 25)

Social media tools provide opportunities for real-time, transparent, and interactive public engagement. It allows economic developers to reach people who may otherwise be challenging to engage or involve - busy professionals, housebound individuals, and others (Block, 2013).

\section{Tourism}

Social media has been heavily employed in the tourism industry. One industry consultant's report suggests "social media and tourism have forever gone together like peanut butter and 
jelly" (Leadsift, 2013). Leadsift monitored 1.1 million online travel conversations over a five day period and found more than 19,000 relevant business opportunities. It also found: only $47 \%$ of those who use social media to plan their vacations stay with their original travel plans; $74 \%$ of users make use of social media while on vacation; and $76 \%$ of users share information on social media about their vacation after they get home (Leadsift, 2013). Economic developers responsible for tourism can use social media platforms in numerous ways for customer engagement and interaction. It's also a vital tool in reputation management, and for building and marketing a community or region brand.

\section{Business retention and expansion}

The role of retaining a community's existing businesses, and ideally helping them expand, is played by many economic developers. As already stated, social media presents great opportunities to create conversations and develop relationships. Traditional business retention and expansion strategies have included business visitation programs - based largely on conducting formal in-person surveys of local businesses - and identifying red-flag issues and responding. Mazier and Wardi (2013) in their webinar presentation Supercharging Business Retention and Expansion With Social Media suggest that these tactics present a "static approach" and are failing because they are time- and resource-intensive, dependent on outreach skills, and have limited impact. Instead, they suggest a "dynamic approach" where economic developers use social media tools to listen and learn from their businesses, and connect with businesses, in an effort to ultimately provide them with solutions and value-added services.

\section{Business assistance}

Economic developers who provide business counseling services can help local businesses improve their chances for success by educating them about the value of being online. As mentioned earlier, ATB Financial (2014) reports that $31 \%$ of small and medium enterprises plan to do more online in the next year. Economic developers can assist by sharing their knowledge of online platforms, hosting workshops and learning opportunities, and modeling best practices online. Economic developers can also support existing companies by using online tools to make available business intelligence data such as labour force availability, demographics and property inventories (Anderson, 2014).

Social media is also a tool for providing customer service. Economic developers need to be prepared for businesspeople who choose to ask a question or make an inquiry online, rather than by traditional phone or e-mail.

\section{Marketing and investment attraction}

Perhaps one of the most talked about uses for social media in economic development is marketing and investment attraction. In Winning Strategies in Economic Development Marketing (Development Counsellors International, 2011), site selectors and executive decision makers 
were asked about their use of social media. When asked which sources of information influence their perceptions of a community's business climate, the top five responses were: dialogue with industry peers, articles in newspapers and magazines, rankings/surveys, meetings with economic development organizations, and business travel. When asked specifically about social media, $38 \%$ of executives stated they do not use social media for business; however it also found younger executives are more likely to use these tools in business (DCI, 2011, p. 20).

With the rapid adoption of social media across the United States and Canada, it's likely the statistics would be quite different today. This is evident in a related report undertaken in 2013. In U.S. Executives' Perceptions of Canada's Business Climate (DCI, 2013), corporate executives with site selection responsibilities ranked social media eighth out of 13 responses when asked what marketing activities they believe would be most effective for Canadian cities to communicate their business advantage.

While the quantitative data from Development Counsellors International does not spell out the case for social media, economic development industry experts agree that social media applications accelerate the process of creating dialogue with industry peers and generate more news articles about a community (Intelegia Group, 2012).

Wright (2012), using the High Performance Economic Development Framework (see Figure 5), spells out four categories of tools available to economic developers; all but one include a component of social media:

1. Base marketing tools to manage, measure, and produce results. These are basic tools that help economic development agencies manage and respond to companies that visit their website, such as email marketing, social media management tools, and presentation templates.

2. Tactics that drive awareness to an organization or community. This involves getting the word out about a community to drive traffic to its website. Tactics include online and print advertising, social media promotion (videos, Twitter posts), earned/placed media, and search engine optimization.

3. Tactics that improve conversion from website to conversation. This encompasses demonstrating value to website visitors and prompting them to contact the economic development organization. Tools may include a blog with user-generated content or a GIS system with property and business analysis.

4. Tactics that bypass the web and go straight to phone calls, face-to-face meetings, and other direct interactions. Examples include trade missions, cold calling and industry trade shows. (Wright, 2012, p. 21-23)

Wright also places a dollar value on each category of tools to demonstrate which provide the biggest bang for the buck (Wright, 2012, p. 24). Using typical spending by economic development agencies for a tactic (such as YouTube video promotion or print advertising) and 
the number of total conversations the tool generates, Wright calculated the typical "cost per conversation." His findings range from $\$ 2$ to $\$ 12,500$ cost per conversation depending on the tactic. The end result: technology-driven solutions cost less and produce more results.

It is clear that using technology to drive conversation presents the most opportunities. If you are currently spending time and budget on items that are not driving traffic to your website, or if you are not implementing tactics to increase the conversation that comes from your website, stop doing them, and start doing things that do. (Wright, 2012, p. 29)

\section{Effective Use of Social Media}

The case for why social media is an important tool for economic developers has been made. Social media tools provide timely, engaging, interactive, targeted and low-cost ways to market a community, gain information, and communicate and build relationships with stakeholders. However, as with other programs or services offered by economic development agencies, to be truly effective, it is critical to have a strategy in place.

\section{Developing a social media strategy}

According to marketing consultant Tyler Seed, "the number one best practice for economic development online is to develop and maintain a cohesive, goal-oriented and measureable web and social media strategy" (Seed, 2013).

The process of developing a social media strategy usually includes the following steps ${ }^{1}$ :

1. Identify goals (aligned with the organization's goals),

2. Set objectives,

3. Research and identify audiences,

4. Develop key messages,

5. Choose social media channels and tactics,

6. Create a content strategy,

7. Allocate budget and resources, and

8. Set measurements and analyze results.

Some economic development organizations, especially government agencies, may also want to include policies and procedures in their strategy. Some organizations find it useful to develop guidelines for staff using social media. Economic developers will also need to take into consideration federal and provincial privacy and electronic communications laws.

Social media strategies, like social media tools, are fluid and ever-changing and should be reviewed on a regular basis.

${ }^{1}$ Daoud, 2014; Durutta, 2014 


\section{Defining the audience}

Social media is about people and relationships. To expertly engage and create conversations online, it's essential to understand the audience. In social media, economic developers are not communicating to the masses, as with traditional marketing, but having a conversation with individuals.

Social media expert Ernest Barbaric (n.d.) recommends creating target market profiles that outline the audience's values and motivations. Creating a "persona" or profile for each audience will help in later developing the tone and type of content to use. The profile includes the target's name, age, gender, attributes, attitudes and an image. It then combines what the person thinks, feels, sees, hears, says, and does. Creating these fictitious profiles will help economic developers know "who" they are talking with online and will assist greatly with content, style and tone.

\section{Developing a content strategy}

Social media is driven by content. Experts agree that a content strategy is essential to be successful. Ideally, this strategy is developed before an economic developer begins using social media tools. What's unique about social media is that each channel has its own community and within that network is its own set of socially acceptable rules, marketing requirements and best practices (Watts, 2013).

The purpose of a content strategy is to define who you are speaking to, where to find them, how to approach them and what to say. There are four components of a content strategy:

1. Define your goals - Identify what you want the content you post to do for your organization;

2. Find your audience - Choose channels where you can organically connect with them;

3. Know how to behave - Learn the socially acceptable practices of the social media channels you've chosen to use; and

4. Create a conversation calendar - Plan and schedule what you are going to say on social media. Keeping your goals in mind, chart out themes using existing information on file, upcoming events, news stories, and more. Plan where you need to develop new, original content. Be prepared to add up-to-the-minute information as needed. (Watts, 2013)

Having a content strategy allows economic developers to be more organized, proactive and timely. It also allows them to:

- ensure the social media tools being used fit into the scope of the overall marketing, communications or program plan;

- allocate and acquire the needed resources, including staffing, technology, and information;

- $\quad$ engage the right individuals (audience); 
- $\quad$ select the most appropriate platforms - knowing the type of content you intend to post will determine which social media tool is best; and

- identify existing, available content that can be used, which saves time and resources. (Smith, 2011)

\section{The importance of branding online}

The importance of online branding cannot be overlooked when developing a social media strategy:

With increased competition for investment dollars, economic development agencies must work on their brand if they are seeking success with digital marketing tools. Breaking through the clutter... is difficult without a brand. It is no longer sufficient for agencies to tell the world their region is the best choice to invest in. Agencies must consistently illustrate why the region is the best option to invest in by using key brand attributes that must be substantiated with curated content. (Intelegia Group, 2012, p. 58)

Barbaric (2013) suggests using a "two-word theme" approach. That is, picking two words that represent your organization or community's brand. The words should represent what you want to be known for. Once these words are determined, they can be used to brainstorm content that fits. They can also be later used to measure results by researching the search terms people use to find an agency's website or social media tools-do the search terms match the two words?

A good online brand is recognizable, memorable and consistent. Economic developers must allocate the appropriate time and resources to ensure they are presenting (or creating, if a strong brand doesn't already exist) a consistent and effective brand online.

\section{Measuring results}

Perhaps one of the most challenging aspects of social media is measuring results. Performance measurement appears to be an area marketers are still uncertain about. Stelzner (2014) found only one in three (37\%) marketers agreed they were able to measure the return on investment for their social media activities.

As social media technology becomes more advanced, so increases the amount of analytical data available. However, an economic development agency must first identify what it is truly trying to achieve, and how to measure it, before beginning to look at data.

The focus in social media measurement has shifted from measuring "Likes" on Facebook or "Followers" on Twitter to measuring quality of content, interactions and actions taken by audiences. Wright suggests measuring website traffic and the number of conversations for investment attraction marketing (see Figure 5).

To get started measuring social media efforts, economic developers should: 
- take time to define social media success;

- develop specific, measurable goals and objectives;

- measure engagement such as comments, shares, or any measure related to your organization's goals;

- start small with an easy-to-handle project;

- learn to measure results rather than activity;

- learn to measure influence rather than popularity;

- $\quad$ use measurement to connect your social media program with your organization's goals;

- use metrics to learn and improve your plan; and

- $\quad$ use measurement to save time. (Paine, 2013)

Effectively measuring social media is an area still under development. Economic developers should stay up-to-date on the latest trends and techniques and continuously update the measurements section of their social media strategy as new approaches become available. As with any program or service, measuring, tracking, and reporting success is critical to ensuring continued funding, sustainability of programs, retention of partnerships, and advancement of the profession.

\section{Resourcing social media}

Without question, implementing a social media strategy takes time and skill. Often, economic developers work alone or in small teams. While many social media tools can save economic developers both time and money, they can also be a strain on human and financial resources.

\section{Staffing}

To be successful using social media, it must be resourced properly. In addition to having excellent written communication skills, economic developers working as social media managers need to:

- $\quad$ be good listeners (social media is about listening as much talking);

- be available outside regular business hours;

- embrace change (social media changes regularly);

- welcome criticism (online feedback can be harsh);

- $\quad$ read, follow the news, and stay current on pop culture, trends, politics and more; and

- perform as well in-person as online (the end goal is to develop in-person relationships with the people you meet online). (Hubbard, 2013)

Economic development agencies must also acknowledge the amount of time staff need to be effective online. Stelzner (2014) found that marketers who spend a minimum of six hours a week on social media reported benefits including improved search engine rankings, increased exposure for their business, more loyal fans developed, and more leads generated. 


\section{Budget}

Social media strategies must also have the appropriate budget. While many social media tools are free or low cost, others such as video have much higher development costs. These expenses, as well as staff time, must be calculated into the overall budget. As a starting point, Wright's (2012) report provides a good overview of economic development agencies' average spending on a variety of tools.

\section{Education, training and best practices}

With the popularity of social media comes a plethora of options for economic developers wishing to learn more and hone their skills. Economic development professional associations in the United States and Canada offer training through webinars, workshops and courses. There are also many websites and blogs offering advice.

Many best practices exist within the economic development profession. Professional associations are now including social media projects in their awards program. Reports from consulting agencies, such as Intelegia's 2012 Canadian American Cities Online Marketing Index, provide valuable examples of economic development agencies that are maximizing the use of social media. Economic developers should also look outside their own industry and research best practices in other sectors.

Because of its ever-changing nature, economic developers should dedicate the time and energy necessary to stay current on social media tools and practices.

\section{Conclusion}

Opportunities abound for economic developers to use social media to achieve their goals. It is clear that the number of individuals and businesses using social media is steadily increasing. While the platforms and tools for social media change constantly, the purpose of social mediamaking connections and having conversations - isn't likely to change or vanish.

There are a number of uses for social media in delivering economic development programs. It is essential that economic development agencies take a strategic approach to using social media to ensure they are making the most effective use of their time and budget. The first step is to understand that social media is about sharing opinions, exchanging information, and having conversations. It is different from traditional marketing channels: social media is about talking with, not at, people.

As with traditional marketing or communications programs, a planned approach is needed. Economic development agencies are encouraged to create social media strategies that are focused, goal-oriented, and measurable. Because social media provides the opportunity to target very specific, often niche, groups of people, audience identification and research is key. One recommended approach is to create profiles or personas for the individuals one wishes to connect 
with online. This will help economic developers better communicate with their audience and choose the most relevant social media channels. It is also recommended that a content strategy be developed and implemented. This will not only save the social media manager time and stress, it will ensure the channels, messages and budget are appropriate and on track for meeting goals.

Measuring the success of any program is essential. Currently, one of the greatest challenges for economic developers using social media is evaluating its effectiveness. Because developing partnerships or attracting investment to a community can take years for results to be seen, it is difficult to measure the impact marketing had on the project. When developing a social media strategy, it is critical to set realistic goals and corresponding metrics that can be tracked and reported upon over time. Economic developers are encouraged to measure not just the quantity of their social media activities, but the quality and results. It is also important to stay current in the field so that when new measurement approaches and techniques are introduced, economic developers can implement them.

Social media offers tools and opportunities that should be embraced by economic development agencies. In a time when resources for economic development are limited - and the expectations for results are high — social media can provide timely, engaging, interactive, targeted and lowcost ways to market a community, gain intelligence, and communicate and build relationships with stakeholders. If implemented strategically, economic developers using social media are sure to see success.

\section{Author Biography}

Sara Chamberlain has worked in the economic development profession for nearly a decade. Currently, she is an Economic Development Officer with the City of Airdrie, one of Canada's fastest growing communities. Sara has Bachelor degrees in political studies and public relations and holds the Ec.D. designation from the Economic Development Association of Canada and is an Accredited Business Communicator through the International Association of Business Communicators.

\section{References}

Anderson, L. (2014, January 17). How EDOs can enable economic development online [Blog]. Retrieved from http://www.iedconline.org/blog/index.php?src=blog\&category=Business\%20Attraction\%20and \%20Marketing

ATB Financial. (2014, February). Running a business hasn't gotten any easier, but technology helps. ATB Business Beat, volume 4, 4-6. 
Barbaric, E. (n.d.). Ultimate guide to advanced target marketing. Retrieved from http://ernestbarbaric.com/ultimate-guide-advanced-target-market-profiles/

Barbaric, E. (2013). The smart guide to social media content strategy [Blog]. Retrieved from http://www.iabc.com/cwb/archive/2013/0313/Barbaric.htm\#printer_friendly

Block, A. (2013). Social media a tool in public participation. University of Waterloo Economic Development Program, Year 1/2 paper.

Canadian Internet Registration Authority (CIRA) (2014). The Canadian Internet. Retrieved from http://cira.ca/factbook/2014/the-canadian-internet.html

Cohen, H. (2011, May 9). Social media definitions [Blog]. Retrieved from http://heidicohen.com/social-media-definition/

Daoud, H. (2014, July 16). 8 essential elements of a social media marketing strategy [Blog]. Retrieved from http://www.socialmediaexaminer.com/essential-elements-social-mediamarketing-strategy/\#more-65114

Development Counsellors International (2011). A view from corporate America: Winning strategies in economic development marketing. Retrieved from http://www.aboutdci.com/winning-strategies/

Development Counsellors International (2013). A view from the Lower 48: U.S. executives' perceptions of Canada's business climate. Retrieved from http://www.aboutdci.com/canadasurvey/

Duggan, M. \& Smith, A. (2014). Social media update 2013. The Pew Research Centre. Retrieved from http://www.pewinternet.org/files/2013/12/PIP_Social-Networking-2013.pdf

Durutta, N. (2014, August 2). Strategic communication planning: Why the basics matter more than ever [Blog]. Retrieved from http://cw.iabc.com/2014/08/02/strategic-communicationplanning-basics-matter-ever/

Economic Developers Association of Canada (2014, May). Membership services update [Presentation]. Retrieved from http://www.slideshare.net/EDAC_ACDE/edac-member-report$\underline{\text { may-2014 }}$

Evans, D. (2010). Social media marketing: The next generation of business engagement. Indianapolis, IA: Wiley Publishing Inc.

Hart, K. (2012, October 26). Why economic developers should be obsessed with social media [Blog]. Retrieved from http://economicdevelopment.org/2012/10/why-economic-developersshould-be-obsessed-with-social-media/ 
Holt, S. (2012). A matter of substance. Communication World, 29(1), 15-19.

Hubbard, D. (2013, July 18). 12 traits of successful social media managers [Blog]. Retrieved from http://www.ragan.com/Main/Articles/46979.aspx

Intelegia Group (2012). 2012 Canadian American cities online marketing index. Retrieved from http://www.slideshare.net/intelegia/2012-canadian-american-cities-online-marketing-index$\underline{15260213}$

Kingsley, C. (2009). Making the most of social media: 7 lessons from successful cities. Retrieved from https://www.mrsc.org/artdocmisc/m58pa_7lessonssocmed.pdf

LeadSift. (2013, September 20). The future of social media \& destination marketing [Blog]. Retrieved from http://leadsift.com/future-social-media-destination-marketing-infographic/

Matthews, L. (2010). Social Media and the Evolution of Corporate Communications. The Elon Journal of Undergraduate Research in Communications, 1 (1), pages 17-23. Retrieved from http://www.elon.edu/docs/eweb/academics/communications/research/02MatthewsEJSpring10.pdf

Mazier, G. \& Wardi, L. (2013, October 28). Supercharging business retention and expansion with social media [Presentation slides]. Retrieved from http://www.slideshare.net/wright0405/iedc-social-media-presentation-25-october2013final

Paine, K. (2013, May 2). Top 10 social media measurement tips. Retrieved from http://www.ragan.com/Main/Articles/46631.aspx

Seed, T. (2012a, February 7). Creative economy marketing with social media [Blog]. Retrieved from http://www.yfactorblog.com/creative-economy-marketing-with-social-media

Seed, T. (2012b, August 22). Attracting talent through social media [Blog]. Retrieved from http://www.yfactorblog.com/attracting-talent-through-social-media

Seed, T. (2013, February 21). Social media monitoring for economic development [Blog].

Retrieved from http://www.yfactorblog.com/social-media-monitoring-for-economicdevelopment

Singh, K. (2014, July 28). Rising social networks you should explore [Blog]. Retrieved from http://mashable.com/2014/07/28/social-networks-on-the-rise/

Smith, I. (2011, June 29). 5 opportunity costs of not having a content strategy [Blog]. Retrieved from http://www.intelegia.com/en/2011/06/29/5-opportunity-costs-of-not-having-a-contentstrategy/ 
Social media. (2014, August 10). In Merriam Webster, an encyclopedia of the Britannica Company. Retrieved from http://www.merriam-webster.com/dictionary/social\%20media

Social networking service. (2014, August 13). In Wikipedia, The Free Encyclopedia. Retrieved from http://en.wikipedia.org/wiki/Social_networking_service

Statistics Canada (2014). Digital technology and Internet use, 2013. Retrieved from http://www.statcan.gc.ca/daily-quotidien/140611/dq140611a-eng.htm

Stelzner, M. (2014). 2014 social media marketing industry report. Retrieved from http://www.socialmediaexaminer.com/

Watts, D. (2013). Why it's critical to have a content strategy before you create a social media profile. Retrieved http://www.iabc.com/cwb/archive/2013/0313/watts.htm

Wright, B. (2012). High performance economic development: How technology and outcomebased metrics will save economic development investment and promotion as we know it. Retrieved from http://www.slideshare.net/wright0405/atlas-high-performance-economicdevelopment-white-paper

Wright, B. (2013, October 22). Economic development marketing: Metrics that matter [Presentation slides]. Retrieved from http://www.slideshare.net/wright0405/social-mediametrics-iedc-web-seminar-presentation 